\title{
The Globalisation of Foreign Aid: Global Influences and the Diffusion of Aid Priorities
}

\author{
Liam Swiss
}

\subsection{INTRODUCTION}

Although countries follow many different pathways to become aid donorsand we witness considerable heterogeneity among donors in terms of where, when, how, and on what they spend their aid funds-there remains a striking degree of similarity among donors. For instance, donors as different as Spain, Poland, Canada, and Japan all espouse some form of support for gender equality in their programming and policies. Many of these similarities derive from what has been referred to as an "emerging global consensus" around different development priorities, yet the processes by which donors come to look and act alike have received limited attention.

To examine this puzzle, this chapter explains why bilateral aid donors often look and act alike, despite their disparate national interests and historiesa phenomenon I have previously labelled "the globalisation of foreign aid" (Swiss 2018). I identify processes that drive this similarity or isomorphism of aid actors and the diffusion of aid priorities-processes that drive the globalisation of aid. Building on earlier research, in this chapter, I reflect on: (1) how the isomorphism of aid institutions and the homogenisation of aid policy represent the effects of these common processes of globalisation; (2) the implications of the globalisation of aid on the 2030 Agenda for Sustainable Development; and (3) how the globalisation of aid contributes to the thread of "contested cooperation" that is woven through this volume.

L. Swiss $(\varangle)$

Memorial University, St. John's, NL, Canada

e-mail: lswiss@mun.ca

(C) The Author(s) 2021 


\subsection{The Globalisation of Aid}

Despite varied interests and motivations, aid donors often think and act alike on a wide array of development policies and programming priorities in the face of otherwise heterogeneous national interests, cultures, development contexts, and organisational structures. Donors frequently acknowledge the puzzling degree of similarity in their approaches - the isomorphism of their practices and institutions-as being reflective of an emerging "global consensus" on things development- or aid-related. My research into this phenomenon labels this "the globalisation of aid" and works to explain the puzzle by drawing upon sociological neo-institutionalism and World Society theory to show how this globalisation is due to the creation, circulation, and enactment of worldlevel models for how aid should be delivered and the priorities on which it should focus (Swiss 2018).

By exploring the globalisation of aid in two domains (gender and security) and across donors at two levels (globally and using a three-country comparison), my findings reveal processes that promote the globalisation of aid at the macro- and micro-levels. At both scales, these processes lead to isomorphism within the aid sector, despite the divergent national interests, histories, and contexts of various donor countries. Here, I focus more on the macro-level processes of globalisation that shape donor policies and priorities, and then briefly introduce the micro-level processes that operate within aid agencies to facilitate the globalisation of aid.

\subsubsection{Macro-Level Globalisation Processes}

The macro-level influences identified build upon the sociological neoinstitutionalist World Society perspective advanced by John W. Meyer and his students (Boli and Thomas 1999b; Meyer et al. 1997; Schofer et al. 2012). A primary focus of World Society research is the explanation of isomorphism among different states and organisations. The empirical literature in this tradition has provided significant macro-sociological evidence of how the influence of global cultural models on states leads to isomorphism or globalisation. World Society researchers show that the increasing isomorphism of states in areas as varied as educational systems, environmentalism, human rights, and legal systems derives from the influence of global actors, treaties, meetings, and networks (Boyle et al. 2015; Cole and Ramirez 2013; Frank et al. 2009; Kim et al. 2013; Nugent and Shandra 2009; Schofer and Hironaka 2005; Schofer and Meyer 2005).

Key factors identified in this literature that are linked to the diffusion of common models and institutions include state ties to international nongovernmental organisations, the timing of global conferences, and the ratification of various international treaties or agendas. The World Society perspective argues that the diffusion of common institutional models is associated with greater ties to such international actors and the timing of such global agendasetting events. Likewise, mimicry and the influence of the behaviour of other 
states are also shown to be a strong factor in promoting the diffusion of global models. To this end, states are shown to be more likely to display isomorphic behaviour when they: (1) are influenced by the behaviour of other states; (2) are more embedded in global networks of international organisations; and (3) aim to comply with global agendas. It is these same three macro-level influences that I identify in my research on the globalisation of aid (Swiss 2011, 2012, 2014, 2016b, 2018) and review here.

\section{Influence of other donors: Mimicry and contagion}

Donors adopt and implement new policy and programming priorities by copying the work of other donors (Swiss 2014, 2018). As perceived donor leaders innovate and implement new policy and programming directions, other donors look to them to inspire their own policy reforms and programming decisions. This emulation of leading donors is in keeping with earlier theories of mimicry and their relationship to institutional isomorphism (DiMaggio and Powell 1983). For instance, Swiss (2018) shows that Sweden-perceived as a leader in gender equality programming in the mid-2000s-was an inspiration for Canadian reforms to their gender policy and practices in that period. Indeed, one could argue that Sweden's 2014 Feminist Foreign Policy (Ministry for Foreign Affairs Sweden 2018) played a significant role in influencing Canada's subsequent advent of its Feminist International Assistance Policy in 2017 (Brown and Swiss 2017; Tiessen and Swan 2018).

Mimicry, in the World Society literature, extends to what researchers refer to as model density - measured using the number of countries or organisations that have adopted a world-level model. In essence, the higher the number of countries that adopt a policy model, treaty, or other institutional forms, the greater the likelihood that other countries will do the same. Similar to contagion effects identified in other literatures, this density effect is evident in aid donors as well, with quantitative evidence showing that the more donor countries adopt a focus on women and gender, the more likely it is that others will do so as well (Swiss 2012). For instance, statistical modelling of the adoption of donor women/gender policies and units in the period from 1968 through 2003 reveals that for every four donors that adopted such policies, the chance of other donors following suit increased by more than 100 per cent (Swiss 2018). This herd mentality among donors demonstrates the clear role for mimicry and contagion in furthering the globalisation of aid.

\section{The DAC and beyond: International organisationsns}

Another key macro-level influence on the globalisation of aid is that of international and inter-governmental organisations (Boli and Thomas 1997, 1999a). In the case of Western bilateral donors, the critical organisation in this regard is the Organisation for Economic Co-operation and Development's (OECD) 
Development Assistance Committee (DAC) (Eyben 2013; Kim and Lightfoot 2011; Swiss 2016a; Verschaeve and Orbie 2018). As has been shown in other sectoral contexts (Alasuutari 2011; Alasuutari and Rasimus 2009), the OECD and its bodies are venues for standards-setting and policy development and act as a forum for donor discussion. In my earlier research, I demonstrate how the DAC's GenderNet working group of donor representatives played a key role in the spread of policies on women in development among donors (Swiss 2012).

By holding donor meetings, developing guidelines, and actively policing DAC donor behaviour through its peer review processes, the DAC shapes donor norms and encourages donors to conform to a specified set of priorities and practices. Indeed, the peer review process has been shown to influence donors to match the "best practices" of other donors as they reform and refine their aid programmes (Ashoff 2013; Carroll and Kellow 2011; Pagani 2002; Verschaeve and Orbie 2016). This is not to say that the peer review process is omnipotent in shaping donor structures and behaviours. As Lim (2014) shows, the first DAC peer review after South Korea joined the DAC contributed to some change in Korea's development cooperation, but many recommendations were difficult to implement. Although peer review involves examination by donor peers from other countries, the process is facilitated through the DAC, and the body of DAC peer review reports over the years provides evidence of a clear role for the DAC in setting standards and encouraging their implementation, by old and new donors alike.

\section{The 2030 Agenda and the global goals: Conferences and treaties}

The final macro-level influence on the globalisation of aid is that of globallevel conferences, treaties, and their associated agendas. In the World Society literature, these treaties, events, and their outcomes have been linked to the diffusion of a variety of policies, models, and institutional forms (Cole 2012, 2013a, b; Swiss 2009; Yoo 2011). For aid donors, these influences have been felt via world-level conferences such as the Beijing World Conference on Women (Hafner-Burton and Pollack 2002; Moser and Moser 2005; Swiss 2012, 2018), which influenced donor responses to gender and development, and more generally worked to shape the global women's movement. Similar conferences and their outcome documents, whether aid-focussed (i.e. the 2005 Paris Declaration on Aid Effectiveness) or not (i.e. the 2015 Paris Agreement on climate change), hold substantial sway with donors. For instance, following the 2005 Paris Declaration, donors quickly embraced aid effectiveness principles such as country concentration and donor collaboration, though the implementation of these principles, in practice, did not always conform to the intent of the declaration (Brown and Swiss 2013; Hyden 2008; Sjöstedt 2013). 
Still, international declarations and agenda-setting conferences are key factors in explaining the globalisation of aid. Since 2000, we have seen this play out most clearly through, first, the Millennium Development Goals (MDGs), and now the Sustainable Development Goals (SDGs) of the 2030 Agenda. For instance, despite the sometimes uneven and problematic adoption of the MDGs by donors (Clemens et al. 2007; Easterly 2009; Thiele et al. 2007), we witness at least a rhetorical, if not practical, adoption of the MDGs as a key factor in shaping donor aid allocation and priorities in a number of areas. Clemens and co-authors discuss how, even if the MDGs were unlikely to be achieved through aid, having them as an aspirational or symbolic target was able to "galvanise" the aid community to act and devote more aid towards the MDG agenda (Clemens et al. 2005). My interviews with aid workers in three donor agencies (Canadian International Development Agency, Swedish International Development Cooperation Agency, and United States Agency for International Development) revealed this same influence, where having gender equality as MDG 3 was reported by donor officials as being a valuable tool for helping advance gender and development as a priority (Swiss 2018). Even though the SDGs of the 2030 Agenda are relatively new, it is likely that this latest set of goals will serve a similar role in shaping donor aid allocation and priorities (Sethi et al. 2017).

\subsubsection{Micro-Level Globalisation Processes}

At the micro-level, the globalisation of aid is discerned by examining processes and mechanisms enacted by the personnel and officials working within aid donor agencies and other development actors. Drawing upon the literature on policy and norm translation, Fejerskov (2018) identifies these processes as "micro-sociological processes of agency" through which aid officials act to translate and adapt ideas into aid agencies. Swiss (2018) highlights five such processes operating within aid agencies that work to connect them to the common policy and programming models which reflect the globalisation of aid: (1) internalisation and certification of models by referring to outside authority; (2) active connections between donors and local and international civil society groups engaged in development; (3) bureaucratic activism where donor officials champion or step outside of their formal duties to promote policy and programming reforms; (4) policy processes driven by the need to have a position on some new policy or issue area for an international or multi-donor meeting or conference; and (5) processes by which donor officials attempt to assert autonomy from their respective ministries of foreign affairs (when the donor agency is a separate entity). Each of these microlevel processes is used by donor officials to justify, explain, enact, and translate common aid priorities and policies across a wide range of donor actors. 


\subsubsection{Why the Globalisation of Aid Matters}

While puzzling, the globalisation of aid might seem a trivial feature of the international aid community. Yet, I argue that these globalisation processes in the aid sector merit further self-critique from aid actors and greater attention from researchers because of three main concerns (Swiss 2018, p. 5).

1. Constraints on acceptable priorities: The globalisation of aid may constrain the potential range of development interventions deemed acceptable by donors and therefore limit recipient countries in how they structure their development interventions. For instance, if the majority of aid donors is primarily interested in supporting health-related development in a country, where does that country turn for support of its other development priorities such as climate change adaptation, renewable energy, or governance reform? More consensus among donors about the priorities of development globally may thus constrain the space for recipient countries to find development cooperation support outside that consensus.

2. Less room for innovation: The globalisation of aid can stymy innovation and new approaches - if a donor consensus exists around a given issue, it becomes more difficult to propose alternative approaches to these issues within aid agencies. The tendency for best practices in aid to lead to cookie-cutter or one-size-fits-all approaches to certain development challenges is emblematic of the risks to innovation or doing development differently. Indeed, even when innovation is encouraged via "grand challenges" or pilot initiatives, consensus begins to emerge around successful innovations, and donors quickly aim to "scale up" the innovation into the latest cookie-cutter solution.

3. Reduced research and analysis: The globalisation of aid leads to a reduced need for donors to undertake research and analysis linked to various priorities and contributes to a shift of donor focus to process rather than developmental concerns. If the globalisation of aid has led donors to adopt a relatively uniform set of aid priorities and approaches, a donor agency has less incentive to ensure that those priorities and approaches are informed directly by local context and development priorities. In this way, the globalisation of aid can contribute to approaches that see donors do development similarly in many contexts rather than valorising the local needs of societies and communities where they work. In extremis, this may lead donors to a focus that ignores local contexts and prioritises donor processes over the actual evidentiary basis for aid interventions.

Each of these limits and constraints underscores the potential downsides of a globalised aid community and reveals why it is important for aid researchers to consider isomorphism among aid agencies and their priorities as a potential risk 
to effective and appropriate aid. Unfortunately, these same possible negative effects of the globalisation of aid are also likely to shape how it influences the 2030 Agenda moving forward, the topic to which I turn in the next section.

\subsection{IMPLications FOR THE 2030 AgENDA}

The globalisation of aid is likely to advance in the context of the 2030 Agenda. SDG priorities will shape aid donors' programming and policies by narrowing their focus on the SDGs; however, this may be less evident than in the past under the MDGs because of the more than doubling of the number of goals. Indeed, with 17 SDGs, the scope of the SDGs may present donors with a wider array of policy and programming priorities to target. This may lead to the appearance of a less isomorphic aid field, but in reality, it might just present a more diverse set of targets at which donors will aim their efforts while still conforming to normative pressures to support the SDGs. The globalised aid consensus will include more potential choices but still constrain donors to work within the ambit of the SDGs.

Taken to its extreme, another potential risk of the globalisation of aid for the 2030 Agenda is that donors will overly focus their efforts on a narrow subset of the SDGs to the neglect of others. This may lead to a patchwork and uneven implementation of the 2030 Agenda. Indeed, with 17 goals, the ability of individual donors - or even donors collectively - to address all of the SDGs in a meaningful fashion is limited. This means that, as aid donor priorities coalesce around certain SDGs, the globalisation of aid may limit the potential to evenly implement the 2030 Agenda. In this respect, the contradiction of having a global agenda imposed through the SDGs that is simultaneously prescriptive but overbroad carries the risk of only a patchwork uptake of the agenda in a globalised aid context. For instance, there is good reason to expect that donors will dedicate more energy and resources to the achievement of certain SDGs and their related targets than others. The focus of SDG 1 on extreme poverty is more likely to attract donor attention and official development assistance (ODA) dollars than SDG 12 and its focus on responsible consumption and production. Add to this the challenge that donors do not always choose the most appropriate aid instruments and modalities to contribute to specific SDGs in a given country, and a globalised aid agenda in support of the SDGs heightens the risk of a mismatch between donor and recipient aims (Rudolph 2017).

Likewise, although there is a wider scope of the substantive development goals under the 2030 Agenda, the influence of SDG 17 to strengthen the implementation of global partnerships for sustainable development may work to constrain donor approaches for supporting the SDGs. By focussing donor efforts on a specified range of modalities such as the use of multi-stakeholder partnerships, support to capacity-building, or efforts to increase policy coherence, SDG 17 provides donors with an outside authority to refer to in justifying their programming decisions. The internalisation and certification 
process outlined above would serve in such cases for donor agency officials to legitimate their policy and programming plans by linking them to support for SDG 17. Although concentrating donor efforts to support the global goals would seem to be an inherently good thing for the achievement of the 2030 Agenda, it also runs the risk of having donors exclude alternative approaches to development that do not meet with the modalities outlined in SDG 17. In this way, the globalisation of aid can blinker aid donors in their programming choices and approaches to partnering. These effects of the globalisation of aid on the 2030 Agenda could play a role in stymying aid/donor innovation in attempting to achieve the SDGs. Although the breadth of SDG 17 and its manifold indicators suggests that almost "anything goes" in order for donors to contribute to the goal, the reality of the wide menu of modalities available to donors may play the opposite role in limiting donor interventions due to donors becoming overly focussed on one or another of the 19 targets of SDG 17.

Another implication of the globalisation of aid on the 2030 Agenda relates to non-DAC donors, South-South cooperation, and new donor countries. The same sorts of globalisation processes I discuss above in the DAC context have been shown to shape new and emerging donors in similar ways, though there still exist significant gaps between the development cooperation of established and emerging donors (Gulrajani and Swiss 2018, 2019). New donor countries respond to similar norms about how to be a donor country, as have the DAC donors, and recent research shows that these normative frameworks are in flux, possibly converging to a new set of ideas of what it means to be a donor, whether DAC or non-DAC (Gulrajani and Swiss 2019). If the globalisation of aid in the 2030 Agenda era brings both conventional ODA donors and South-South cooperation partners into a common set of priorities and practices, this may lead to greater coherence of development cooperationin its many guises-in support of the SDGs and the broader 2030 Agenda. Although donor norms for ODA providers and South-South cooperation partners have not always aligned previously, a period of contested cooperation may see the globalisation of aid shape norms for both that become increasingly similar.

\subsection{The Globalisation of Aid and Contested Cooperation}

Whereas the globalisation of aid is likely more reflective of collaboration in the development assistance field, contestation can be viewed as a driver of new and emerging aid policy priorities and programming trends. This section considers the globalisation of aid's relationship to both collaboration and contestation and briefly suggests how it is implicated in this volume's arguments around "contested cooperation" in the 2030 Agenda era. 
Collaboration leads to the globalisation of aid. As donors and other international actors convene to address particular development issues or challenges, the common approaches, priorities, and guidelines they devise contribute significantly to the globalisation of aid. This globalisation of aid-donors sharing common policies and priorities-contributes to what Gulrajani and Swiss identify as the norms of donorship (Gulrajani and Swiss 2018, 2019). These norms - the agenda of a globalised aid community-represent the result of collaboration among an array of aid actors, experts, researchers, and communities. Successful collaborations lead to shared understandings, the diffusion of common practices and models, and the isomorphism of aid actors and practices. Yet, it is clear that the aid sector and its practices can be fickle and ebb and flow through a series of "new and improved" policies and best practices on what seems like a more frequent schedule.

Here, I think it is important to consider the globalisation of aid not as a uniform adoption of one static approach to aid by donors, but instead as a dynamic series of such priorities, policies, and models that fall in and out of favour, not only because of collaboration in the aid sector, but also via contestation. Contestation, as many chapters in this volume illustrate, is a key part of the foreign aid sector globally. Despite the globalisation of aid, there is consistent contestation in the development assistance sector, which can lead to a heterogeneous adoption or implementation of norms and aid priorities (ColdRavnkilde et al. 2018). Indeed, even when donors arrive at a set of priorities around an issue such as aid effectiveness, gender, or security, the practices of aid are highly contested and sometimes diverge sharply from organisation to organisation, donor to donor (Brown and Swiss 2013). These gaps might be exaggerated by greater contestation in the donor space. More recently, conventional DAC donors have witnessed such contestation from emerging donors and providers of South-South cooperation (Gulrajani and Swiss 2018). Such contestation of the DAC status quo has been perceived in recent years via the growing role of the United Nations Development Cooperation Forum, despite some of its shortcomings (Verschaeve and Orbie 2016).

Contested cooperation, in this sense, represents the cyclical dynamic of the coming and going of vogues of aid priorities and practices that represent the globalisation of aid. The aid sector is embedded in the negotiation, adoption, and eventual rejection of globalised priorities and approaches, which are eventually contested and then jettisoned in favour of a new approach or fad that has evolved from contestation and collaboration by other aid actors. This contested cooperation framework-interacting with the globalisation processes I outline above-makes for a valuable lens through which to understand persistence and change in development cooperation.

Common aid models emerge from new collaboration, are contested between, through, and within aid agencies, and may eventually achieve a form of dominance that results in the seeming isomorphism and diffusion of aid priorities, which I argue represent the globalisation of aid. Arguably, the globalisation of aid, and the isomorphism and diffusion it represents, is 
a key outcome of the contested cooperation that this volume identifies in the global aid sector. With the 2030 Agenda, we are likely to witness these globalised outcomes around a variety of aid practices and priorities before the closing of the SDGs in 2030. Indeed, as the variety of actors involved in the contested cooperation that helps drive this process widens, the globalisation of aid will likely touch upon many more donors, development non-governmental organisations, and aid recipients as 2030 approaches.

\section{REFERENCES}

Alasuutari, P. (2011). The governmentality of consultancy and competition: The influence of the OECD. In G. Solinis \& N. Baya-Laffite (Eds.), Mapping out the research-policy matrix: Highlights from the first International forum on the social science-policy Nexus (pp. 147-165). Paris: UNESCO Publishing.

Alasuutari, P., \& Rasimus, A. (2009). Use of the OECD in justifying policy reforms: The case of Finland. Journal of Power, 2(1), 89-109.

Ashoff, G. (2013). 50 years of peer reviews by the OECD's Development Assistance Committee: An instrument of quality assurance and mutual learning (DIE Briefing Paper 12/2013). Bonn: German Development Institute / Deutsches Institut für Entwicklungspolitik (DIE).

Boli, J., \& Thomas, G. M. (1997). World culture in the world polity: A century of international non-governmental organization. American Sociological Review, 62(2), 171-190.

Boli, J., \& Thomas, G. M. (1999a). INGOs and the organization of world culture. In J. Boli \& G. M. Thomas (Eds.), Constructing world culture: International nongovernmental organizations since 1875 (pp. 13-49). Stanford, CA: Stanford University Press.

Boli, J., \& Thomas, G. M. (1999b). Constructing world culture: International nongovernmental organizations since 1875. Stanford, CA: Stanford University Press.

Boyle, E. H., Kim, M., \& Longhofer, W. (2015). Abortion liberalization in world society, 1960-2009. American Journal of Sociology, 121(3), 882-913.

Brown, S., \& Swiss, L. (2013). The hollow ring of donor commitment: Country concentration and the decoupling of aid effectiveness norms from donor practice. Development Policy Review, 31(6), 737-755.

Brown, S., \& Swiss, L. (2017). Canada's feminist international assistance policy: Game-changer or fig leaf? In K. A. H. Graham \& A. M. Maslove (Eds.), How Ottawa spends, 2017-2018 (pp. 117-131). Ottawa, ON: School of Public Policy and Administration, Carleton University.

Carroll, P., \& Kellow, A. (2011). The OECD: A study of organisational adaptation. Cheltenham: Edward Elgar Publishing.

Clemens, M. A., Kenny, C. J., \& Moss, T. J. (2005). The millennium development goal aid targets, and the costs of over-expectations. Sustainable Development Law \& Policy, 6(1), 58-84.

Clemens, M. A., Kenny, C. J., \& Moss, T. J. (2007). The trouble with the MDGs: Confronting expectations of aid and development success. World Development, 35(5), 735-751. 
Cold-Ravnkilde, S. M., Engberg-Pedersen, L., \& Fejerskov, A. M. (2018). Global norms and heterogeneous development organizations: Introduction to special issue on new actors, old donors and gender equality norms in international development cooperation. Progress in Development Studies, 18(2), 77-94.

Cole, W. M. (2012). Human rights as myth and ceremony? Reevaluating the effectiveness of human rights treaties, 1981-2007. American Journal of Sociology, 117(4), 1131-1171.

Cole, W. M. (2013a). Strong walk and cheap talk: The effect of the international covenant of economic, social, and cultural rights on policies and practices. Social Forces, 92(1), 165-194.

Cole, W. M. (2013b). Government respect for gendered rights: The effect of the convention on the elimination of discrimination against women on women's rights outcomes, 1981-2004. International Studies Quarterly, 57(2), 233-249.

Cole, W. M., \& Ramirez, F. O. (2013). Conditional decoupling assessing the impact of national human rights institutions, 1981 to 2004. American Sociological Review, 78(4), 702-725.

DiMaggio, P., \& Powell, W. W. (1983). The iron cage revisited: Institutional isomorphism and collective rationality in organizational fields. American Sociological Review, 48(2), 147-160.

Easterly, W. (2009). How the millennium development goals are unfair to Africa. World Development, 37(1), 26-35.

Eyben, R. (2013). Struggles in Paris: The DAC and the purposes of development aid. European Journal of Development Research, 25(1), 78-91.

Fejerskov, A. M. (2018). Development as resistance and translation: Remaking norms and ideas of the Gates Foundation. Progress in Development Studies, 18(2), 126-143.

Frank, D. J., Hardinge, T., \& Wosick-Correa, K. (2009). The global dimensions of rape-law reform: A cross-national study of policy outcomes. American Sociological Review, 74(2), 272-290.

Gulrajani, N., \& Swiss, L. (2018). Donor proliferation to what ends? New donor countries and the search for legitimacy. Canadian Journal of Development Studies / Revue canadienne d'études du développement, 1-21. https://doi.org/10.1080/022 55189.2019 .1543652$.

Gulrajani, N., \& Swiss, L. (2019). Donorship in a state of flux. In I. Olivié \& A. Pérez (Eds.), Aid power and politics (pp. 199-222). London: Routledge.

Hafner-Burton, E., \& Pollack, M. A. (2002). Mainstreaming gender in global governance. European Journal of International Relations, 8(3), 339-373.

Hyden, G. (2008). After the Paris declaration: Taking on the issue of power. Development Policy Review, 26(3), 259-274.

Kim, S., \& Lightfoot, S. (2011). Does "DAC-ability" really matter? The emergence of non-DAC donors: Introduction to policy arena. Journal of International Development, 23(5), 711-721.

Kim, M., Longhofer, W., Boyle, E. H., \& Nyseth Brehm, H. (2013). When do laws matter? National minimum-age-of-marriage laws, child rights, and adolescent fertility, 1989-2007. Law \& Society Review, 47(3), 589-619.

Lim, S. (2014). Compliance with international norms: Implementing OECD DAC principles in South Korea. Globalizations, 11(6), 859-874.

Meyer, J. W., Boli, J., Thomas, G. M., \& Ramirez, F. O. (1997). World society and the nation-state. American Journal of Sociology, 103(1), 144-181. 
Ministry for Foreign Affairs Sweden. (2018). Handbook: Sweden's feminist foreign policy. https://www.government.se/4abf3b/contentassets/fcl15607a4ad 4bca9l3cd8dllc2339dc/handbook-swedens-feminist-foreign-policy.

Moser, C., \& Moser, A. (2005). Gender mainstreaming since Beijing: A review of success and limitations in international institutions. Gender and Development, 13(2), $11-22$.

Nugent, C., \& Shandra, J. M. (2009). State environmental protection efforts, women's status, and world polity: A cross-national analysis. Organization \& Environment, 22(2), 208-229.

Pagani, F. (2002). Peer review as a tool for co-operation and change. African Security Review, 11(4), 15-24.

Rudolph, A. (2017). The concept of SDG-sensitive development cooperation: Implications for OECD-DAC members (DIE Discussion Paper 1/2017). Bonn: German Development Institute / Deutsches Institut für Entwicklungspolitik (DIE).

Schofer, E., \& Hironaka, A. (2005). The effects of world society on environmental protection outcomes. Social Forces, 84(1), 25-47.

Schofer, E., Hironaka, A., Frank, D. J., \& Longhofer, W. (2012). Sociological institutionalism and world society. In E. Amenta, K. Nash, \& A. Scott (Eds.), The Wiley-Blackwell companion to political sociology (pp. 57-68). Malden, MA: Wiley-Blackwell.

Schofer, E., \& Meyer, J. W. (2005). The worldwide expansion of higher education in the twentieth century. American Sociological Review, 70(6), 898-920.

Sethi, T., Custer, S., Turner, J., Sims, J., DiLorenzo, M., \& Latourell, R. (2017). Realizing agenda 2030: Will donor dollars and country priorities align with global goals? A baseline report. Williamsburg, VA: AidData.

Sjöstedt, M. (2013). Aid effectiveness and the Paris declaration: A mismatch between ownership and results-based management? Public Administration and Development, 33(2), 143-155.

Swiss, L. (2009). Decoupling values from action: An event-history analysis of the election of women to parliament in the developing world, 1945-1990. International Journal of Comparative Sociology, 50(1), 69-95.

Swiss, L. (2011). Security sector reform and development assistance: Explaining the diffusion of policy priorities among donor agencies. Qualitative Sociology, 34(2), 371-393.

Swiss, L. (2012). The adoption of women and gender as development assistance priorities: An event history analysis of world polity effects. International Sociology, 27(1), 96-119.

Swiss, L. (2014). Mimicry and motives: Canadian aid allocation in longitudinal perspective. In S. Brown, D. R. Black, \& M. den Heyer (Eds.), Rethinking Canadian (pp. 101-124). Ottawa, ON: University of Ottawa Press.

Swiss, L. (2016a). A sociology of foreign aid and the world society. Sociology Compass, $10(1), 65-73$.

Swiss, L. (2016b). Space for gender equality in the security and development agenda? Insights from three donors. In S. Brown \& J. Grävingholt (Eds.), The securitization of foreign aid (pp. 188-211). Basingstoke: Palgrave Macmillan.

Swiss, L. (2018). The globalization of foreign aid: Developing consensus. London: Routledge. 
Thiele, R., Nunnenkamp, P., \& Dreher, A. (2007). Do donors target aid in line with the millennium development goals? A sector perspective of aid allocation. Review of World Economics, 143(4), 596-630.

Tiessen, R., \& Swan, E. (2018). Canada's feminist foreign policy promises: An ambitious agenda for gender equality, human rights, peace, and security. In N. Hillmer \& P. Lagassé (Eds.), Justin Trudeau and Canadian foreign policy (pp. 187-205). Cham: Springer International Publishing.

Verschaeve, J., \& Orbie, J. (2016). The DAC is dead, long live the DCF? A comparative analysis of the OECD Development Assistance Committee and the UN Development Cooperation Forum. The European Journal of Development Research, 28(4), 571-587.

Verschaeve, J., \& Orbie, J. (2018). Ignoring the elephant in the room? Assessing the impact of the European Union on the Development Assistance committee's role in international development. Development Policy Review, 36(S1), O44-O58.

Yoo, E. (2011). International human rights regime, neoliberalism, and women's social rights, 1984-2004. International Journal of Comparative Sociology, 52(6), 503-528.

Open Access This chapter is licensed under the terms of the Creative Commons Attribution 4.0 International License (http://creativecommons.org/licenses/by/4.0/), which permits use, sharing, adaptation, distribution and reproduction in any medium or format, as long as you give appropriate credit to the original author(s) and the source, provide a link to the Creative Commons license and indicate if changes were made.

The images or other third party material in this chapter are included in the chapter's Creative Commons license, unless indicated otherwise in a credit line to the material. If material is not included in the chapter's Creative Commons license and your intended use is not permitted by statutory regulation or exceeds the permitted use, you will need to obtain permission directly from the copyright holder.

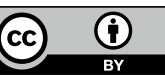

